\title{
The Death of the Big Deal and Implications for Technical Services
}

Angela Maranville

West Virginia University, angela.maranville@mail.wvu.edu

Karen Diaz

West Virginia University, karen.diaz@mail.wvu.edu

Follow this and additional works at: https://researchrepository.wvu.edu/faculty_publications

Part of the Collection Development and Management Commons, Scholarly Communication Commons, and the Scholarly Publishing Commons

\section{Digital Commons Citation}

Maranville, Angela and Diaz, Karen, "The Death of the Big Deal and Implications for Technical Services" (2021). Faculty \& Staff Scholarship. 2965.

https://researchrepository.wvu.edu/faculty_publications/2965

This Article is brought to you for free and open access by The Research Repository @ WVU. It has been accepted for inclusion in Faculty \& Staff Scholarship by an authorized administrator of The Research Repository @ WVU. For more information, please contact ian.harmon@mail.wvu.edu. 


\title{
THE DEATH OF THE BIG DEAL AND IMPLICATIONS FOR TECHNICAL SERVICES
}

\author{
Angela Maranville and Karen Diaz
}

\begin{abstract}
In recent years, a growing number of libraries have canceled or unbundled their "Big Deal" journal subscriptions - those subscriptions that include a full package of digital journal titles for one discounted cost. This started as an affordability problem but has slowly morphed into a challenge from libraries demanding a new pricing structure that accommodates and spurs the growing open access movement.

The change has caused a variety of challenges for technical services units including the increased need for user data, increasingly complicated workflows as they manage partial subscriptions, new interactions with consortia, and ongoing campus conversations. Whether the library is seeking to simply unbundle due to budget constraints, or push for new models such as "read and publish", there is a tremendous impact on the work of technical services units.

This chapter will explore the rationale and growth of the Big Deal, how it is breaking, four case studies on breaking Big Deals, a brief discussion of new transformative agreements, new challenges for consortia, and implications for technical services units moving forward.
\end{abstract}

Keywords: Big Deal; unbundling; technical services; scholarly publishing; serials crisis; journal subscription; Open Access

\section{RATIONALE AND GROWTH}

The term "Big Deal" refers to journal subscription licenses that libraries have with publishers of scholarly journals who publish hundreds or thousands of

Technical Services in the 21st Century

Advances in Library Administration and Organization, Volume 42, 195-214

Copyright (C) 2021 Emerald Publishing Limited

All rights of reproduction in any form reserved

ISSN: 0732-0671/doi:10.1108/S0732-067120210000042014

195

This author accepted manuscript is deposited under a Creative Commons Attribution Noncommercial 4.0 International (CC BY-NC) licence. This means that anyone may distribute, adapt, and build upon the work for non-commercial purposes, subject to full attribution. If you wish to use this manuscript for commercial purposes, please contact permissions@emerald.com. 
scholarly journals and sell access to them through one bundled price for all. Frazier coined the term in 2001, which gives us a date to pinpoint when these arrangements started becoming popular (Frazier, 2001). Ironically, his article was a caution to libraries against growing too dependent upon this new model in which he foresaw several problems developing in scholarly publishing. To understand the rationale and growth of the Big Deal, one must look to the transition publishers and libraries made from a print-based journal subscription model to a digital-based subscription model which started shortly before Frazier spoke out (Kim \& Koehler, 2007).

In the print model, a library paid for a title which could be in only one location. Thus, if it wanted a title to be available in multiple locations it would subscribe to the title multiple times. In a digital environment, suddenly a library could buy the title once but have it available in multiple locations, meaning a potential loss of revenue for publishers. Additionally, the meaning of a subscription took on new challenges. In a print environment, canceling a subscription meant that a library would continue to keep the issues of the journal for which it had already paid on its shelves but would stop receiving new titles. In the digital environment, when the issues did not sit on library shelves or local servers, canceling could either mean access to everything would be lost or only access to new issues would be lost. In a print environment, a library would fulfill interlibrary loan (ILL) requests by walking to the shelf, pulling the issue of the journal down, taking it to the copy machine to copy the article requested, and mailing the paper copy through the mail. In time, that copy became a scan that could be sent through email, but still, there were a large number of steps required to share material with other libraries. In the digital environment, all of these steps became simple keystrokes on a computer that could be dispensed within seconds making sharing across libraries much more simple and prevalent. These new factors caused concern for both libraries and publishers regarding the impacts of this new format. No longer would a simple subscription transaction suffice, but now a new type of negotiated license for each title was required to spell out what libraries could do with the content, with whom and how they could share the content, and exactly what a subscription meant when it came to back files. Negotiating these licenses title-by-title was overwhelming for both the publisher and the library. Thus, bundling the titles into packages made life easier for everyone. One negotiation, multiple titles.

From this step, two additional things began to happen. First, libraries started looking to their consortia to do much of the work of the negotiation. This allowed for strength in numbers - by ensuring the publisher would have many buyers through the consortia, they might be more willing to offer lower prices per package which was a boon to libraries. Many publishers benefitted from this arrangement in needing to negotiate with only one entity, rather than dozens or hundreds of libraries simultaneously. Secondly, because of the bundled packages, publishers began working directly with customers rather than through journal vendors as had been past practice. Because individual titles no longer required special marketing, the serial vendor "middlemen" became less relevant. While the process was smoother, the loss of complication in the market also led to "lock-in" of the process, just as Frazier predicted. Publishers were the only place where a library 
could gain access to a journal, and so libraries increasingly had to accept what the publisher offered often by signing a multiyear agreement to stabilize pricing and reduce inflation. Sometimes publishers would only give concessions if a library would sign a nondisclosure agreement (NDA).

Because of the proliferation of NDAs, "almost no systematic information on prices paid for the bundles supplied by large commercial publishers has been publicly available" (Bergstrom, Courant, McAfee, \& Williams, 2014, p. 1). Because libraries could not share financial arrangements, clouding of a journal's true value or fair price occurred.

Through several years of surveys of ARL libraries, Strieb and Blixrud (2014) found these pricing structures were most common across libraries:

- Historic spend in which publishers provide a price quote to a library based on the historical spend of that library in a print environment

- Aggregate subscription whereby a publisher bases the price on the amount of material to which a library subscribed

- Tiered in which publishers charge fees based on the size (FTE of students and faculty) of the institution

- Usage whereby publishers charge fees based on how much content the institution uses.

The historic spend model proved to be the most common in a recent survey, even though virtually no libraries continue to purchase print (Strieb \& Blixrud, 2014). For years, libraries have complained about these incongruous pricing structures, lack of transparency, and general beholdenness to publishers who set the terms of large subscription packages.

But according to Bergstrom et al. (2014), the real problem that has frustrated libraries and that has slowly led to more coordinated effort around bringing clarity to costs and changing how the subscription model works is that:

Big deals that were initially attractive have become less so, a decade later, as publishers have increased the prices of their bundles by $5-7 \%$ per year. A bundle whose price increased by $5.5 \%$ per year would have doubled its price between 1999 and 2012, whereas over the same period the US consumer price index rose by $38 \%$. (p. 9428)

Simply put, journal packages have outpaced Consumer Price Index (CPI) in inflationary costs and become too expensive for many libraries whose budgets have flattened at best or have decreased at worst. The Big Deal packages further exacerbate library budgets in that they take up an increasingly large percentage of the libraries' budget; so if large cuts are called for, it is impossible to reach the goal of decreased spending without touching the Big Deals.

\section{BREAKING OF THE BIG DEAL}

When Frazier (2001) called for libraries to resist the Big Deal at their onset, he recommended practices that included strategies around maintaining print subscriptions 
alongside electronic. He argued that using a variety of strategies would keep a lock-in with these Big Deals from happening. Certainly, 20 years later it is impossible to imagine that any library would purposely keep print titles in lieu of electronic. So while Frazier's strategy is no longer relevant, his goals are highly prescient. Libraries do now work directly with publishers as he predicted and the lock-in effect has taken place. The hyper-inflation rate of journals (especially those by for-profit publishers) has led many libraries to not only complain about the burden of the costs of these bundles but has seen many libraries start to step away from these deals. It has been a slow and painful process.

As far back as 2004, Cornell University passed a resolution in their faculty senate acknowledging there was a "crisis in the costs of journals in the sciences and social sciences" (Duranceau, 2004, p. 1). Other universities followed suit and began bringing the issue of this growing problem around costs and the need to find new and sustainable economic models in scholarly publishing to the awareness of their campuses.

In 2011, Southern Illinois University walked away from all of its bundled deals (Nabe, 2017). By 2015, the movement away from Big Deals started gaining enough traction that the SPARC organization began tracking libraries that were canceling these deals through their Big Deal Cancellation Tracking site (SPARC, 2019). This has allowed libraries to track and communicate with other libraries which are currently working or have worked through these issues providing pathways to approach their own cancelations. To date, nearly 50 libraries and consortia have self-reported Big Deal cancelations.

Most libraries have unbundled because of the burgeoning cost and with it the challenge those costs pose in terms of requiring a greater percentage of shrinking library budgets. But another consequence of the Big Deals taking an increasingly large portion of those budgets as they shrink is a further shift in the marketplace away from dollars being available for small publishers (Nabe, 2017). Thus the Big Deals have also served (along with other factors) to push out smaller publishers and further consolidate which publishers are working in the scholarly space.

Article after article has been written in the past decade decrying the Big Deal. The themes of the complaints have been consistent and persistent. The major complaints relate to the rate of inflation of the package costs and the inflexibility they force during times of financial constraint. Toni states, "The long-term model becomes a sort of trap that compels libraries to maintain their set of journals unmodified for several years even if their budget is continuously decreasing" (2012, p. 6). While Fund (2017) elaborates:

\footnotetext{
...libraries found themselves in a situation in which large chunks of their budgets are locked in not only with only a few publishers but also increasingly with large volumes of content with limited usage. Multi-year agreements have multiplied the lock-in effect libraries find themselves in. "All you can eat" made a number of libraries obese. (p. 2)
}

The major concern in unbundling is the uncertainty of knowing how such a step will impact the campus in terms of research output and any other unintended consequences. Early reports indicate that unbundling might not be as 
catastrophic as feared. When the Université de Montréal unbundled packages, they "realized that, at best, barely more than a third of the periodicals included in most Big Deals are truly of use" (Gagnon, 2019, p. 10). Toni notes that when an Italian Health Institute consortium unbundled Elsevier in 2011 they lost $50 \%$ of titles but only saw a $20 \%$ decrease in overall number of downloads (2012). Nabe (2017) notes that:

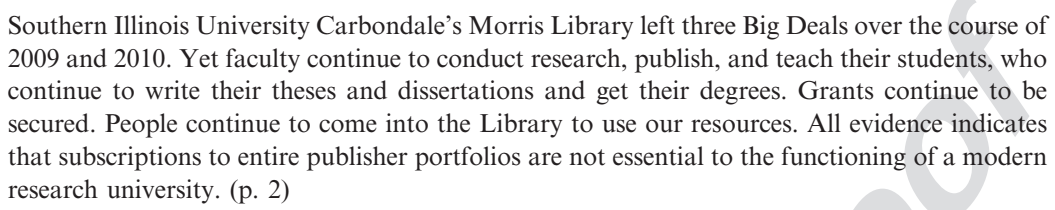

Iowa State reported that the result of unbundling had little effect on ILL usage as was a concern (Pederson, Arcand, \& Forbis, 2014). This experience was similar at the authors' institution in the wake of unbundling three major Big Deals.

\section{FOUR EXPERIENCES WITH BREAKING BIG DEALS}

\section{Overview and Rationale}

Given the challenges of the Big Deal and an early sense that unbundling might not be as catastrophic as feared, more libraries might consider this approach. These case studies provide insights into strategies in working through unbundling as it is not a simple or straightforward process. Four separate libraries' experiences follow: West Virginia University (WVU), which is the authors' home institution, Florida State University (FSU), the University of Missouri (MU), and Iowa State University (ISU).

WVU Libraries was forced by fiscal restrictions to unbundle three Big Deals in the last three years due to the collection development budget being cut by a third in just two years. To meet these reductions, WVU Libraries unbundled Wiley in 2016 and Springer Journals and Elsevier's ScienceDirect in 2018 resulting in an overall savings of $\$ 1.4 \mathrm{M}$. During this time, the Libraries also shifted from a "just in case" collection development strategy to a "just in time" philosophy. Rather than purchasing materials "just in case" a patron might use it, the Libraries are primarily purchasing items as they are requested or "just in time". This allows the library to meet the needs of patrons while controlling collection development spending.

FSU has been involved in unbundling or canceling four major journal publisher packages over several years. FSU canceled Wiley in 2014 and brokered a deal with lower pricing in 2015, canceled Springer in 2016 and similarly arranged a deal with lower pricing in 2017, unbundled Taylor \& Francis in 2018, and unbundled Elsevier's ScienceDirect package in 2019 reducing overall costs by $50 \%$. In every circumstance, FSU canceled publisher packages due to recurring yearly limitations on the collections budget (Ziegler, personal communication, September 3, 2019). 
Fiscal necessity also drove MU's decision to unbundle. The library experienced a nearly $20 \%$ cut in their collections' budget in fiscal year (FY) 2017 and anticipates a 30\% cut in FY20. In response to the FY17 cut, MU canceled mainly serials as they accounted for the majority of collections' spending. Overall, contracted resources accounted for $83 \%$ of the collections' budget in FY17. To meet the reduction, MU reduced their Wiley, Springer, and Elsevier Big Deals by $\sim 15 \%$ and completely dropped their deal with Sage choosing instead to purchase specific subject collections and individual titles to meet their needs (Hutchinson, personal communication, September 20, 2019).

ISU's experience is somewhat unique in that it was not driven by budget restrictions, but by values. Curtis Brundy (2019), Associate University Librarian for Scholarly Communications and Collections states:

The [Wiley] package was unbundled because its value did not justify its cost. Publishers, including Wiley, will justify the high price they charge for their packages by citing the cost per use. However, evidence continues to mount that download statistics are inflated, inaccurate, and not representative of actual demand for the underlying content. (personal communication,

September 12, p. 1)

This theory is strongly supported by many libraries' experiences with very low ILL requests after a cancellation. This can be due to many factors but inflated COUNTER reports are surely contributing. As with the WVU and FSU unbundlings, ISU saved money by paying for only those titles needed.

\section{Decision \& Data Analysis}

WVU used a data-informed approach for title selection in both 2016 and 2018. The approach in 2016 had to be done quickly and used a Weighted Average, which weighted overall use twice as high as the cost per use (CPU). In 2018, time allowed for an initial overlap analysis project to first remove any titles that were available in other packages. Next, we calculated the average usage using 3-4 years of usage pulled from COUNTER JR1 reports; as well as the cost per average use, which is average use divided by the cost; and included data from the 1 Science 1 Figr report to create a selection criteria. The 1 Figr report was a new addition which had not been used for the Wiley unbundling. Specifically, it contained the number of citations and publications for these journals using Scopus as the data source. 1Figr data was added as a metric to reflect which titles were actually being used by our faculty in an effort to be more responsive to the needs of the campus. The 1Findr data was science heavy but worked very well for interdisciplinary journal packages, particularly Science Direct.

Once these data were gathered, they were presented to the Libraries' Collections Advisory Committee (CAC), whose role it is to make the final selections. Using the data above and their knowledge of departmental needs, the CAC selected the final Springer and ScienceDirect titles for retention. This is in marked contrast to the Wiley unbundling, which was conducted using a data-only approach due to time and budgetary constraints in 2016 and was accomplished by two individuals. 
In contrast, FSU's decision-making and title selection process involved both the faculty and the administration. As Roy Ziegler (2019), then Associate Dean for Collection Services stated,

There has always been a broader decision-making process in our library when it comes to major changes because we believe it's important to give the University's administration and the faculty an opportunity to participate (personal communication, September 3, p. 2).

Ziegler (2019) goes on to say that:

When it comes to any curtailment of library resources, we have to explain what we've already done to save money. This comes before there's any discussion of canceling major journal packages. In the years when the budget situations were especially dire, the Dean of Libraries called upon the Faculty Senate Library Committee to form a faculty-led task force to recommend a prioritized list of library materials that could be canceled or allocations reduced. The goal was to have as little impact on the University's research and curriculum as possible. (personal communication, September 3, p. 2)

Once the decision had been made to cut or unbundle a Big Deal, FSU conferred with their legal counsel to determine if they could break the contract due to financial hardship and indeed, left all of their deals midway through multiyear contracts. FSU also used a data-informed approach relying on ranked journal usage statistics as well as impact factor, cost, and CPU for both one-year and three-year rolling averages. Faculty had the option to request low-usage titles for selection, but other titles in that subject area would be canceled to offset the cost of keeping the low-usage title. This loophole was requested by faculty but never used. Ultimately, FSU ranked by usage and selected to keep until they hit their target figure (Ziegler, personal communication, September 3, 2019).

MU's experience was unique in that they kept enough titles to maintain a Big Deal but still reduced their spending to meet the budget reduction. According to Associate University Librarian for Acquisitions, Collections, and Technical Services, Corrie Hutchinson (2019), they developed five principles to guide their work:

(1) No disciplines or collections types can be exempt.

(2) Usage will be one factor, but not the only factor, when considering cancellations.

(3) Access will be prioritized over ownership.

(4) ILL will remain an effective, efficient means of acquiring materials not owned.

(5) Transparency will be a priority. (personal communication, September 20, p. 5)

Immediate cuts were suggested to subject librarians who were assisting with the process for titles with high CPU although each publisher approached the negotiations differently. For example, MU was able to cut $15 \%$ of their spend with Springer and roughly $67 \%$ of the titles while still retaining favorable contract terms (Hutchinson, personal communication, September 20, 2019). This resulted in MU being able to purchase the content that was highly used and still stay within their budget restrictions.

MU's Elsevier deal was complicated by being involved in a four-campus deal with the other University of Missouri schools. MU spent months negotiating a 
price, which enabled them to keep the Freedom Collection while still meeting their spending reduction. There was a feeling that by negotiating to retain the Freedom Collection, MU's patrons didn't really feel the cuts to Elsevier as they would have in a full unbundling. Conversely, Wiley was a straightforward negotiation with the publisher agreeing to an overall spending cut without losing access to the full collection. Titles were selected as they were with Springer using $\mathrm{CPU}$ as the driving metric, working in concert with subject librarians. In contrast, Sage was unwilling to negotiate, which resulted in a full unbundling with usage and subject-based needs driving title and collection selection (Hutchinson, personal communication, September 20, 2019).

ISU also adopted a data-informed approach to their cancellation using download statistics, author publications and citations, open access (OA) availability, program areas, journal price, and backfile access. After adopting a target spend much as WVU and FSU did, they selected the highest rated journals based on their analysis, stopping when they met their target (Brundy, personal communication, September 12, 2019).

\section{Campus Conversations}

After the lessons learned from the initial unbundling of Wiley in 2016, WVU approached the unbundling of Elsevier's ScienceDirect in 2018 with an eye toward transparency and campus engagement. A plan was formulated by the Libraries' Dean to approach the deans and department chairs of affected colleges with a presentation explaining the overall fiscal situation, as well as a comparison between the percentage of titles affected $(2.8 \%)$ and the percentage of budget affected $(26 \%)$. This comparison is a stark example of the discrepancy between cost and perceived value to campus, and when coupled with the imposed budget reduction, clearly explained the necessity of unbundling. In addition, an explanation of modern-day ILL was included, explaining how faculty could easily access titles to which the library would no longer subscribe. These conversations, as well as those with WVU administration, were carried out in Spring 2018, and while not entirely alleviating the angst of losing instant access to titles, went a long way toward creating a common understanding across the university.

Talking points for subject liaisons were also created to assist with the tough conversations spawned by the unbundling. An additional step taken after title selection was completed in late 2018 was the release of a communication to WVU as a whole from the Dean of Libraries explaining the unbundling and included a listing of titles retained, which titles were available through backfiles or aggregators, and which titles needed to be accessed through ILL.

FSU's approach was even more transparent, using banners on the library's homepage, regular outreach by subject librarians, and campus-wide emails. Similar to WVU, FSU also created a system for complaints or concerns and talking points for their subject librarians, which promoted a uniform message. They also worked to keep the Faculty Senate Library Committee, and by proxy the full Faculty Senate, informed by regularly updating them on the ongoing 
cancellation. Another tactic used by FSU in 2016 was how they framed the conversation. To quote Ziegler (2017):

As a sales and marketing strategy, framing the issue as mediated and unmediated access avoided the negative connotations associated with the word "cancellation." In fact, the word "cancellation" was never mentioned in communications to the campus community. The university wasn't losing access to 1,300 leased access titles, only changing the manner in which access was being requested and retrieved. (p. 5)

FSU like MU also shared a contract for ScienceDirect, in this case with several state institutions, so communication was deemed essential. The Dean of Libraries passed regular updates to other stakeholders across the states. These updates and the eventual cancellation were met with some disbelief and worry that costs might go up for institutions remaining in the contract to offset FSU's cancellation (Ziegler, personal communication, September 3, 2019).

MU, while having no formal communication plan, also took a transparent approach with the University librarian announcing the cuts campus-wide in late FY16/early FY17. Additionally a LibGuide was created that contained the history of the budget reductions, the five previously mentioned principles guiding the collection's reduction, cancellation updates, and title lists. MU also reached out to the campus community with surveys to gather feedback on the cancellations, asking if ILL was an option, and about core titles. This feedback was not anonymized so individuals with concerns could be contacted. Overall, there was some negative feedback, but with reductions happening across campus, most faculty understood the necessity for the cancellations (Hutchinson, personal communication, September 20, 2019).

ISU, like WVU and FSU, had also unbundled other Big Deal packages. Based on feedback after these cancellations in which FSU experienced little impact on teaching and learning and drawing on the experiences of other libraries, they chose not to engage the campus community regarding the unbundling of Wiley. ISU did create basic talking points that were shared with liaison librarians to be used when contacted about cancellations, and the collections coordinator served as primary contact for the project as a whole. Additionally, in light of the reduced visibility of the Wiley unbundling, ISU set aside a budget reserve to add back faculty requests should they occur (Brundy, personal communication, September 12, 2019).

\section{Publisher Negotiations}

For WVU, publisher negotiations with Wiley began late in 2016 and as noted earlier, were rushed due to the budget reduction being announced mid-fiscal year. Libraries' administration and university procurement were involved from the inception, and while talks were ongoing, access to Wiley journals and two other associated databases were turned off. To further complicate matters, WVU had just changed their subscription model, moving from the Core Collection to the Database model. This difficulty was overcome by Wiley agreeing to give reduced pricing. However, once titles were selected, Wiley billed at a higher rate than previously negotiated stating that too many titles had been cut. Due to financial constraints, additional titles could not be added and ultimately a subpar bargain 
was struck. The agreement did however provide access to our selected titles but is under scrutiny by the CAC for possible renegotiation in 2020 .

Negotiations with Elsevier began in March 2018 with a visit from Elsevier representatives to meet with the Dean of Libraries, the Vice Provost of Academic Support, and the Assistant Vice President of Procurement, Contracting and Payment Services, as well as Libraries' staff involved in the unbundling. This initial visit was a chance for Elsevier to get a firsthand look at the fiscal landscape and future projections for WVU. It also provided a platform to jointly plan our path forward. Elsevier was asked to provide several proposals by the end of May, but their initial proposals fell short of our fiscal needs and a counterproposal was submitted a week later. After some back and forth, an agreement that met the target spend was reached by obtaining minor concessions from Elsevier, most notably in negotiating a reduced content fee. This concession allowed patrons instant access to more content and benefited both parties. However, unlike MU, access to the Freedom Collection wasn't retained. The Freedom Collection is a collection that can't be purchased individually but is instead offered in conjunction with a full subscription to ScienceDirect and has been traditionally used to sweeten the Big Deal.

FSU used a bilateral approach to their various publisher negotiations. If they could negotiate a deal with better terms, cancellation could be avoided. If not, cancellation was the plan. In some cases as noted above, FSU was able to leave a deal and later negotiate a more beneficial contract and return. Neither Wiley nor Springer was willing to negotiate until they had lost revenue, but returning to the deal did require FSU to buy back into the deal with one-time money, a luxury not every library has. Taylor and Francis never made any concessions, but due to structural realignment of the contract, FSU was able to opt for partial relief by purchasing only what they required (Ziegler, personal communication, September 3, 2019).

FSU's experience with Elsevier was unlike WVU's in that they "could never get the publisher to put a reasonable offer on the table" (Ziegler, personal communication, September 3, 2019, p. 14). Much like WVU experienced, Elsevier seemed committed to their business model of tying everything to a complete ScienceDirect subscription for preferential pricing and access to the Freedom Collection. FSU attempted to negotiate reduced recurring costs with one-time purchases of journal backfiles and eBooks much as they had done with Wiley and Springer. This failed and made cancellation a necessity. Ziegler (2019) states, "It never felt like we were coming together to negotiate. We just seemed to talk to each other" (personal communication, September 3, p. 14). FSU believed this disconnect was due to the simultaneous negotiations taking place in Europe and with California Digital Library (CDL) and will welcome the opportunity to reopen negotiations with Elsevier in the coming years.

Once MU knew that cuts were on the horizon, they reached out in late Spring 2016 to every Big Deal publisher they had a subscription with to begin negotiations and request a $20 \%$ cut. One lesson learned from this proactive approach is that while many publishers are willing to deal with you, they aren't able to provide next year's pricing or able to finalize deals until closer to the end of the 
calendar year. The majority of the MU deals were finalized in mid-Fall 2016 with Springer and Wiley readily negotiating and allowing cuts of $\sim 15 \%$ while retaining some elements of the Big Deal as mentioned earlier (Hutchinson, personal communication, September 20, 2019). Sage, also noted earlier, would not negotiate which led to cancellation. Negotiations with Elsevier were similar for both WVU and FSU in that the initial offers were unreasonable and not responsive to the needs of the institution. Indeed, there is a perception from the publisher that the ScienceDirect content is so valuable that libraries should cut all other resources to maintain the content. This philosophy is shortsighted and has contributed to many cancellations as shown here.

MU, like FSU and WVU, was negotiating for price rather than OA or any other concessions. In 2016, much like WVU, MU hadn't any OA tenets or mandates in place, and OA wasn't a consideration during negotiations. Another difficulty encountered during the negotiation was lack of experience and limited staffing. MU's negotiations were completed by a single librarian in every case except Elsevier, which while efficient, was a large burden for a relatively new librarian (Hutchinson, personal communication, September 20, 2019).

ISU's approach to negotiation with Wiley was proactive and forward thinking and can be considered a reflection of the changes in the relationship between libraries and scholarly publishing. According to Brundy (2019),

Our basic stance was that Wiley needed to offer terms that were not punitive, meaning they should reflect the value of what we are buying and not Wiley's desire to keep us in the Big Deal Package (personal communication, September 12, p. 4).

ISU asked for the terms below:

(1) A discount from list price

(2) Year-to-year term

(3) Unlimited ability to cancel and swap titles

(4) Standard backfile access

(5) Monthly report on ISU article processing charges (APC) spending in Wiley hybrid titles

(6) 3\% inflation cap (Brundy, personal communication, September 12, 2019, p. 4)

ISU received:

(1) $10 \%$ discount from list price

(2) Year-to-year term

(3) Unlimited ability to cancel and swap titles

(4) Standard backfile access

(5) $4 \%$ inflation cap (Brundy, personal communication, September 12, 2019, p. 5)

While not what initially negotiated for, the ISU Wiley deal is far better than many currently in place and provides a jumping off point for other libraries in substandard agreements. 


\section{Opportunities and Challenges}

The three years of budget reduction at WVU have presented unforeseen opportunities. First was a far better understanding of the resources the Libraries subscribed to and the budget required to support those resources. This opportunity was also a challenge as this in-depth analysis was time-consuming and impacted more than the electronic resources unit. These former Big Deals all must be scrutinized each year as they are renewed to identify poor performers as well as titles to be added to the package, placing a strain on the decision-makers and the ILL staff.

Another opportunity was the discovery of the 1Fldr and 1Figr reports, both of which have been useful for more than collection development. Yet another is the opportunity to discuss OA, scholarly communications, and sustainability issues within the library with the Faculty Senate, university administration, and the campus. After the cuts and in the wake of CDL dropping Elsevier because they could not reach a deal, faculty are much more interested in the evolving path of publishing and scholarly communication. Another opportunity has been the chance to better educate the faculty on ILL and how it has improved. Many faculty had the perception that using ILL would be inconvenient, time-consuming, and downright slow. ILL data was used to show them that instead access via ILL is convenient, intuitive, and fast. Overall, this experience has led to better librarycampus communications, with faculty and staff developing a better understanding of how the library works and becoming more engaged partners in these processes.

As mentioned above, another challenge which WVU encountered was the need to do in-depth data analysis, including running overlap analysis and creating spreadsheets to rank various metrics. Fortunately, WVU has a data support unit within technical services that has been able to do some of this preliminary work. At least one publisher offered to supply some of the analysis but by the time they had offered, the internal analysis was complete. Many libraries don't have the staffing to handle this sort of analysis and are going into negotiation without essential data.

A common challenge area for both WVU and MU was the lack of experience with negotiations. This is common throughout the library world as librarians are asked to interpret more and more complex contracts as well as negotiate multimillion-dollar contracts. Larger institutions such as WVU can rely on their procurement team and legal counsel, but as the stakes get higher, the mistakes can be dire and have the potential to not only tie libraries to costly deals but also increase the possibility of legal liability.

Yet another common challenge was outreach, both internally and externally. Every library encountered this and most were able to transform it into an opportunity for education and understanding. WVU was able to take the lessons learned from the Wiley unbundling, which happened very quickly and was not entirely transparent, and successfully coordinated communication externally with campus stakeholders and internally with concerned liaison librarians. The Dean of Libraries was instrumental in setting expectations for transparency and following through. This transparency has opened doors on campus for further conversation and educated both internal and external stakeholders to the complicated realities facing a twenty-first century library. 
The unbundling of Elsevier in particular presented FSU with many opportunities. One, which is similar to WVU's, is a path forward to discuss OA, scholarly communications, and sustainability issues within the library. Another opportunity was the chance for FSU to assume a leadership role with other libraries who are considering leaving a Big Deal. They are, in effect, paying it forward, because FSU benefited from the knowledge of libraries that had previously unbundled and were willing to share their experiences. According to Ziegler (2019),

We would never have had the courage to proceed if we hadn't been in direct contact with other libraries that had actually gone through it and were willing to talk about their experience (personal communication, September 3, p. 17).

Another opportunity, which began as a challenge and is currently benefiting other libraries including WVU, was the development of a new service point to expedite article loan processing. FSU worked with Atlas Systems, Inc., Reprints Desk, and their own programmers to create a system to meet the needs of researchers who require article access more quickly than traditional ILL can provide. This innovation is a prime example of challenges forcing adaptations that can benefit all.

FSU faced the same challenge that all libraries who considered breaking a Big Deal did: the unknown. Ziegler (2019) says it well, "Loss of seamless access to a large amount of heavily used content is frightful" (personal communication, September 3, p. 19). Thorough planning to cover all eventualities and constant communication is necessary to allow you to successfully travel this road. Once you have unbundled, you will then be able to gather data on the impact of the cancellation and assess the damage or rewards. If, as was the case at WVU, the savings from comparing the unbundling savings to the ILL costs have been extraordinary, you know that your hard work has paid off for both the library and the university.

FSU was also challenged by not knowing when they would lose access to the Freedom Collection (Ziegler, personal communication, September 23, 2019). As mentioned earlier, the Freedom Collection is only available to customers with a subscription to a required amount of ScienceDirect titles and is typically heavily used across campuses. FSU was granted access during negotiations, which dragged out in part due to Elsevier sending a standard contract that lacked state and university requirements. WVU also experienced difficulty and delay with the initial contract offered, causing lengthy delays in signing and increased work for library, procurement, and legal staff.

One opportunity from the unbundling that is indirectly related to the experiences of MU, ISU, and WVU was the creation of a consortium group to share experiences in negotiating with a special emphasis on Big Deals. The Greater Western Library Alliance (GWLA) group met regularly to discuss unbundling, changes in scholarly communications and publishing, and new publisher purchasing models. A second related opportunity that has arisen from these unbundlings is that some publishers seem more amenable to compromise. As Hutchinson (2019) states,

Now that other libraries have made cuts to the big deals, the sacred cow of collections' budgets, it has helped the market adjust and publishers are more willing to make deals than they were in 2016 (personal communication, September 20, p. 23). 
Hutchinson (2019) also goes on to say:

The "serials crisis" has been going on for years and it won't change unless we stop buying them at an annual $6 \%$ price increase. I hate losing the access, but know that we are in an unsustainable environment and something has to give. (personal communication, September 20, p. 23)

While this attitude is still evolving as both libraries and publishers are finding their way forward, there are hints of an end to business as usual.

MU, like FSU and WVU, was able to use this opportunity to educate their faculty on the cost of journals, the publishing process, and OA opportunities. Often libraries and the work they do are unseen, and the loss of instant access has provided a platform where faculty and librarians can interact and learn from each other with the hope of creating a more informed working relationship.

MU encountered a host of challenges, some of which have been previously mentioned. One of the most difficult to navigate was the impression that leaving a Big Deal would damage the research capability of a research library. In fact, WVU encountered this challenge too. The concern that after all the cuts the library would no longer be able to support the university mission is pervasive and one that is difficult to eliminate. This concern contributes to an additional challenge, which is the internal battle among liaison librarians to keep resources for their assigned discipline. These librarians have a vested interest in supporting their constituents and cuts such as these can lead to heated discussions which are another area where transparency is tantamount.

One additional challenge MU faced was an outdated allocation model. Cuts were made based on a data-informed model, but there was no way to measure the impact to specific discipline areas aside from STEM. The model is still in place, but with staff cuts, which were also a byproduct of the budget reductions, there has been no opportunity to revise the current model (Hutchinson, personal communication, September 20, 2019).

ISU's opportunities echoed those listed previously with a singular difference. As the only library unbundling for ethical reasons rather than fiscal necessity, they were able to repurpose some of the savings to bolster OA programs (Brundy, personal communication, September 12, 2019).

\section{TRANSFORMATIVE AGREEMENTS}

Concurrent with the shift away from the Big Deal is the move by libraries to search for something better, both ethically and fiscally. Welcome Plan S! Plan S arrived with the launch of cOAlition $\mathrm{S}$, a European initiative to promote OA, in September of 2018. Plan S (2018) has one primary principle:

With effect from 2021, all scholarly publications on the results from research funded by public or private grants provided by national, regional, and international research councils and funding bodies must be published in Open Access Journals, on Open Access Platforms, or made immediately available through Open Access Repositories without embargo. (p. 1)

Simultaneous with the push to OA, Plan $\mathrm{S}$ brings transformative agreements to the forefront, supporting them as a way for traditional publishers to transition 
to OA (Plan, 2018). Since the Plan S announcement, at least 41 agreements representing 16 publishers, from the largest to smaller society publishers, have been signed according to the ESAC Initiative (Efficiency and Standards for Article Changes) (n.d.), which reflects a huge upswing since tracking began in 2015. In fact, transformative agreements are up 333\% since 2018 (ESAC, n.d.). The most recent signing was the Carnegie Mellon University (CMU) and Elsevier groundbreaking agreement that notably provides an avenue for CMU research to be free of paywalls (Carnegie Mellon, 2019).

So what is a transformative agreement? Transformative agreements are contracts, which seek "to shift the contracted payment from a library or group of libraries ... away from subscription-based reading and toward open access publishing" (Hinchliffe, 2019, p. 1). They center around four main principles: cost, copyright, transparency, and transitioning to OA. These principles aim to move library agreements toward OA where authors retain their copyright, and prices are transparent as well as repositioning contracts to pay for publishing rather than for reading scholarship (Hinchliffe, 2019). With this great increase, the agreements are evolving rapidly with the publishers developing their own agreement language and their own specific models. Some examples are membership agreements, deposits, offsetting, Read and Publish (RAP), Publish and Read (PAR), and Subscribe to Open.

One of the most talked about models in the last year is the University of California (UC) Transformative Model. Based on the UC Pay it Forward study in 2016, the model contains many of the tenets of a transformative agreement. However, UC didn't stop there but expanded on them most significantly by adopting a "multipayer" model splitting the cost between the library and the author (An Introductory Guide, n.d). This model has been used to negotiate both unsuccessfully and successfully most notably with Elsevier and Cambridge, respectively. While this isn't the first transformative agreement in the United States, it is perhaps the most well-known as UC made the decision in early 2019 to cancel Elsevier's ScienceDirect, much like ISU did, for ethical reasons. Only time will tell how transformative agreements will evolve over time, but UC as well as others have presented models that can be built on and are clearly being emulated, based on the recent successful negotiation between CMU and Elsevier as noted above.

\section{CHANGES IN CONSORTIA}

The pressure to unbundle isn't just being felt by individual libraries but also by consortia, long time partners of publishers (Carbone, 2007). Big Deal costs are also rising for consortia forcing individual libraries to leave the consortial deal as budgets continue to shrink in turn placing pressure on the consortia. In fact, all three of WVU Big Deals were part of consortial agreements and are now individual deals because the consortia were no longer able to bargain for us. Berstrom notes that "Commercial publishers have not been able to induce most research libraries to sign big deal contracts, and the number that do so has fallen between 
2006 and 2012" (Bergstrom et al., 2014, p. 9429). This disconnect, where one size no longer fits all, has led some consortia to consider changing the way they negotiate. This sea change has the potential to require consortia to embrace the analysis and evaluation of Big Deal usage prior to negotiations and to explore models not built on historical print pricing (Carbone, 2007) such as à la carte models or subject-based smaller packages. Most importantly, there needs to be an acceptance that Big Deals no longer work for everyone, and if a consortium still wishes to represent a library, the publisher and the consortium must be willing to strike a deal (or many small deals) which is responsive to every budget situation.

This situation occurred last year during a consortium negotiation in which WVU was involved where a subgroup of libraries wished the consortium to pursue an a la carte deal with prices below list and low inflation rates for a variety of reasons but mainly fiscal necessity. The consortium did broach the topic with the publisher but was ultimately rebuffed as the publisher would not come to the table under those terms. One main sticking point was that the publisher didn't recognize the subgroup as being part of the consortium. One can also assume like many publishers they also chose not to license for a lower price (Carbone, 2007). As we move forward in this landscape of increasing unbundling, up 33\% from 2018 to 2019 according to SPARC's Big Deal Cancellation Tracking (SPARC, 2019), publishers will need to adopt a more flexible approach and create multiple "Little Deals" which while more onerous for publishers, will allow struggling libraries to subscribe and count as a plus in the sales column. Doing this through consortia might also reduce some of the workload for publishers. Some additional examples of alternate Big/Little deals include deals based on the value of electronic content, the usage of journals by affiliated researchers, the value of journals within the bundle, offsetting the cost for libraries assuming a long-term preservation role, and tying inflationary increases to annual inflation (Carbone, 2007).

Library consortia and libraries are also beginning to issue FOIA requests to gain better information on the prices they are paying in order to walk into negotiations with publishers better equipped to ensure they are not over-paying or being taken advantage of. Also the SPARC organization keeps a knowledge base of publicly available data on Big Deal costs for libraries to aid those negotiating costs with publishers. Consortia also need to add central evaluation of large bundles to their role of negotiator. It is no longer enough to get a good price; libraries also need to understand the value these subscriptions are bringing to their campuses (Jurczyk \& Jacobs, 2014). The UC system's CDL has proposed metrics that libraries can use to analyze value of journals at a consortium level as well as at a local level (Blecic, Wiberley, Fiscella, Bahnmaier-Blaszczak, \& Lowery, 2013), although it's not clear if many consortia have taken up this work.

Some consortia are also recognizing the need to explore new purchasing models. One example of this is the GWLA Offset Task Force, which was created in June 2018 to locate and explore possible transformative agreements to pilot in the consortium. The task force, which consists of librarians from various GWLA institutions, has explored a variety of transformative agreements from different 
publishers and has in many cases met with the librarians and publishers responsible for negotiating the agreement. This exploration has paid dividends and has led to GWLA offering the Annual Reviews Subscribe to Open plan currently in a 2020 pilot.

Another response to pressure being placed on consortia is the creation of licensing principles. Consortia such as GWLA are exploring creating their own principles to guide their negotiations building from examples such as MIT's Framework Document (MIT Libraries, 2020), CDL's Licensing Guidelines and License Agreement Checklist (California Digital Library, 2019a, 2019b), the University of North Texas Manifesto (UNT Libraries n.d.), and the University of Washington's Licensing Principles and Expectations for Vendors (University of Washington Libraries, 2019). These principles are another step toward leveling the playing field between libraries, consortia, and publishers.

\section{CHANGES IN TECHNICAL SERVICES}

While instrumental in savings and ethically advantageous, leaving a Big Deal affects more than the end users. The impact on technical services units are varied but appear to fall into these large categories: staffing, management of holdings, negotiations, data analysis, and ILL workloads.

With the advent of the Big Deal in the early 2000s, technical services units were able to downsize as much of the work maintaining the libraries' holdings was handled by the publisher and the catalog. Now that libraries around the world are leaving the Big Deal, the need for more staff is clear, but often going unanswered as those downsized position lines have long been absorbed into the other library departments or are gone from the library budget completely. Anecdotally, at WVU the current technical services unit was created by merging several decentralized units into one centralized unit in 2015. At its high water mark in mid-2016, the unit had 20 employees. Now due to retirements, internal shifting, and budget reductions, the unit is down to 16 positions. This scenario is becoming more common as libraries across the United States struggle to maintain parity in a time of reduced funding.

Arguably the biggest impact of leaving a Big Deal on technical services is an increased need for hands-on management of the journals in the catalog or knowledge base. One of the primary advantages of the Big Deal was that several thousand journals were handled as one subscription or, in the case of a knowledge base, one package or collection. Leaving a Big Deal means manually closing out the coverage of those titles and updating holdings records so titles are discoverable. This work is labor-intensive and depending on staffing levels may take several months to complete during which time patrons and staff are confused by incorrect coverage dates, which exacerbates the angst of losing a journal package. Additionally, workflows must be revised to track the purchased titles, the post-cancellation access, the titles which change publishers, and those that move to OA. Frankly, workflows after a Big Deal are altered, increased, and particularly difficult to absorb for short-staffed units. To quote Hutchinson (2019), 
"It takes a lot of work to spend less money" (personal communication, September 23 , p. 1).

In the unbundled environment, libraries subscribe to hundreds of individual titles either from the publisher or from a subscription agent rather than the one easy-to-manage subscription. These titles must be reviewed individually for performance each renewal year, which leads to much more data analysis and significantly lengthens the time needed to review. To date, there are not appropriate tools that have made this work automatic or simple for libraries. Most are having to develop their own homegrown methods for this analysis. Complicating matters are the titles that "come with" several others as a set and the length of time it takes to get updated pricing from the publisher. While libraries leaving the Big Deal likely make more work for the publisher, the delays in response time that often transpire can't always be attributed solely to that.

Another impact is the necessity for more frequent negotiations. Historically, Big Deals were often offered in multiyear contracts, which resulted in fewer negotiations and contract reviews saving time for both the publisher and libraries. Once a library has left a Big Deal, the resulting contract is rarely over 2 years in length. This requires coming to the table more frequently, taking higher level staff away from day-to-day activities and interrupting workflows. These negotiations often require closer working relationships with library administration, business offices, university procurement, and university legal counsel; thus increasing the workload of those units as well.

Data analysis is touched on throughout this chapter both during unbundling and after. Data analysis is necessary to evaluate the assessment metrics such as usage, $\mathrm{CPU}$, impact factor, number of faculty citations and publications among others. After unbundling, metrics such as ILL requests and turnaways are also necessary to analyze. While some technical services units are prepared to do this work, many smaller units are stretched thin. MU, for example, lost staff in their budget reduction, a loss which still hampers the unit. WVU has created a data support unit within its technical service division.

Another data analysis workflow necessitated by the unbundling is the need to keep the campus community informed for the sake of transparency. In the case of FSU, this required constant review of journal usage and turnaways. At WVU, the transparency occurred through internal and external communication and a faculty wish list. As Ziegler (2019) states, "Because of our service commitment to faculty, we had to monitor the situation closely in case titles had to be reinstated" (personal communication, September 23, p. 5). Often these communications are managed by library administration or subject librarians, but those individuals in turn rely on technical services to provide the analyzed and even visualized data to make it friendly to a non-library audience.

One last impact of unbundling is the intensified relationship that is needed between technical services and interlibrary loan operations. As mentioned earlier, many of these Big Deals were heavily used and now patron access is dependent on ILL. At FSU, use of the new Expedited Article Service transferred work to the ILL department. WVU has also seen an increase in overall ILL requests up by $38 \%$ in 2019 since the unbundling of Springer and ScienceDirect which has altered how 
their work is done. What is important now is ongoing analysis of ILL data with subscription data to ensure the shift remains the most economical option for the library along with providing appropriate service levels for the campus.

\section{LAST THOUGHTS}

As Mackie-Mason has declared, after many years of fretting and complaining about the Big Deal, we as a community in the realm of scholarly publishing appear to have finally reached a "tipping point" (2019). Clearly the Big Deal is either breaking or transforming. Maybe we will see both happen in time. For right now, libraries either seem to be in the camp of transforming their Big Deals to tip the publishing landscape toward open when they have sufficient continued funds to maintain a Big Deal, or they are in the camp of unbundling Big Deals either to manage their budgets or to try to force cost reductions by publishers.

One thing that has not changed yet is the lack of any coherent pricing strategy or negotiation strategy. Both libraries and publishers are experimenting with new models to try to determine exactly what the value of scholarly publishing is to its consumers. Libraries have yet to find the breaking point in journal cancellations, and publishers have yet to find the breaking point in what they can extract from libraries. Nondisclosure agreements continue to cast an air of mystery and take us no closer to true understanding of value.

There are a variety of opportunities in the midst of these confusing times. One is a renewed need for libraries to engage in deep conversation with faculty around not only spending practices of the library but also in the publishing practices of faculty. Another is for libraries and publishers to engage in deep conversation around value and pricing structures of journals. And certainly there are opportunities for scholars to engage with publishers around how their labor is being used and valued.

Roy Ziegler (2019) of Florida State University Library nicely sums up where many libraries are or have recently been:

When you can no longer pay, there's a moment of horror and clarity: we need to get out of here; we have to be smarter. It will take a lot of effort to reset but we must be active managers in the stewardship of our collections. Waking up to this realization is the start. (personal communication, September 23, p. 6)

\section{REFERENCES}

An introductory guide to the UC model transformative agreement (n.d.). Retrieved from https://osc. universityofcalifornia.edu/open-access-at-uc/publisher-negotiations/negotiating-with-scholarlyjournal-publishers-a-toolkit/an-introductory-guide-to-the-uc-model-transformative-agreement/. Accessed on November 19, 2019.

Bergstrom, T. C., Courant, P. N., McAfee, R. P., \& Williams, M. A. (2014, July 1). Evaluating big deal journal bundles. Proceedings of the National Academy of Sciences, 111(26), 9425-9430. doi: 10.1073/pnas. 1403006111

Blecic, D. D., Wiberley, S. E., Fiscella, J. B., Bahnmaier-Blaszczak, S., \& Lowery, R. (2013). Deal or No deal? Evaluating big deals and their journals. College \& Research Libraries, 74(2), 178-194. doi: $10.5860 / \mathrm{crl}-300$ 
California Digital Library. (2019a, September 3). CDL license agreement checklist. Retrieved from https://cdlib.org/resources/vendors/license-agreement-checklist

California Digital Library. (2019b, September 19). CDL licensing Guidelines for vendors. Retrieved from https://cdlib.org/resources/vendors/licensing-guidelines/

Carbone, P. (2007). Consortium negotiations with publishers - past and future. LIBER Quarterly, 17(2). doi:10.18352/lq. 7880

Carnegie Mellon University and Elsevier Reach Transformative Deal. (2019, November 21). Retrieved from https://www.library.cmu.edu/cmu-elsevier/news. Accessed on November 22, 2019.

Duranceau, E. F. (2004). Cornell and the future of the big deal: An interview with ross Atkinson. Serials Review, 30(2), 127-130. doi:10.1016/j.serrev.2004.02.002

Efficiency Standards for Article Changes (ESAC). (n.d.). Agreement registry. Retrieved November 19, 2019, from https://esac-initiative.org/about/transformative-agreements/agreement-registry/

Frazier, K. (2001, March). The librarians' dilemma: Contemplating the costs of the "big deal". Retrieved from http://www.dlib.org/dlib/march01/frazier/03frazier.html

Fund, S. (2017). Choosing independence or feeding the beast? The big deal and small or society publishers. Against the Grain, 29(1). doi:10.7771/2380-176x.7705

Gagnon, S. (2019). Journal publishers big deals: Are they worth it? Against the Grain, 29(2). doi: $10.7771 / 2380-176 x .7747$

Hinchliffe, L. J. (2019, April 23). Transformative agreements: A primer Retrieved from https://scholarlykitchen.sspnet.org/2019/04/23/transformative-agreements/. Accessed on November 19, 2019.

Jurczyk, E., \& Jacobs, P. (2014). What's the big deal? Collection evaluation at the national level. Portal: Libraries and the Academy, 14(4), 617-631. doi:10.1353/pla.2014.0029

Kim, C. S., \& Koehler, B. M. (2007). Moving the big deal. Journal of Electronic Resources in Medical Libraries, 4(1-2), 5-14. doi:10.1300/J383v04n01_02

Licensing Principles and Expectations for Vendors. (2019, April 11). Retrieved from https://www.lib. washington.edu/cas/licensing-principles-and-expectations-for-vendors. Accessed on November 12, 2019.

MacKie-Mason, J. (2019, May 3). The push for open access is finally reaching a tipping point. World.edu. Retrieved from https://world.edu/the-push-for-open-access-is-finally-reaching-a-tipping-point/

MIT Framework for Publisher Contracts. (2020, February 19). Retrieved from https://libraries.mit.edu/ scholarly/publishing/framework/

Nabe, J. (2017, April 10). After the big deals are done. Against the Grain, 29(1). Retrieved from https:// against-the-grain.com/2017/04/v29-1-after-the-big-deals-are-done/

Pederson, W. A., Arcand, J., \& Forbis, M. (2014, October 14). The big deal, interlibrary loan, and building the user-centered journal collection: A case study. Retrieved from http://lib.dr.iastate. edu/cgi/viewcontent.cgi?article $=1064 \&$ context $=$ libcat_pubs

Plan, S. (2019, September 4). Retrieved from https://www.coalition-s.org/principles-and-implementation/. Accessed on November 19, 2019.

SPARC. (2019, November 12). Big deal cancellation tracking. Retrieved from https://sparcopen.org/ our-work/big-deal-cancellation-tracking/

Strieb, K. L., \& Blixrud, J. C. (2014). Unwrapping the bundle: An examination of research libraries and the "big deal. Portal: Libraries and the Academy, 14(4), 587-615. doi:10.1353/pla.2014.0027

Toni, F. (2012). Leaving Elsevier's "big deal": An evaluation of the Italian National Institute of Health experience inside the Bibliosan Consortium. Presented at 4th International Conference on Qualitative and Quantitative Methods in Libraries, Limerick, Ireland, 2012. Retrieved from http://eprints.rclis.org/17042/

University of Washington Libraries. (2019, April 11). Licensing principles and expectations for vendors. Retrieved from https://www.lib.washington.edu/cas/licensing-principles-and-expectationsfor-vendors

UNT Libraries. (n.d.). UNT Manifesto: Expectations for library vendors. Retrieved from https:// library.unt.edu/collection-management/unt-manifesto-expectations-library-vendors/

Ziegler, R. (2017). Big deal whack-A-mole. Against the Grain, 29(2). doi:10.7771/2380-176x.7749 